Review Article

\title{
Court Obstetric - Pediatric Issues: Evidence-Based Practice
}

\author{
George Gregory Buttigieg* \\ University of Malta, Malta
}

${ }^{*}$ Corresponding author: Buttigieg George Gregory, Faculty of Medicine and Surgery, University of Malta, The Glen, Russett Street, Kappara, San Gwann, SGN 4432, Malta, E-mail: george.g.buttigieg@um.edu.mt

Citation: Buttigieg GG (2017) Court Obstetric - Pediatric Issues: Evidence-Based Practice. J Pediatr Dis Neonatal Care 1: 101

Article history: Received: 13 June 2017, Accepted: 05 September 2017, Published: 07 September 2017

\begin{abstract}
The article reviews the impact (or lack of it) of Evidence-Based Practice on obstetric - pediatric jurisprudence within the remit of the Bolam test. It briefly reviews the judicial outcome of the classical 1957 Bolam v Friern Hospital Management Committee which led to the Bolam test and of the 1998 Bolitho $v$ City \& Hackney Heath Authority, leading to the Bolitho "enriching" of Bolam. Stressing that the legal standard of practice is essentially set by doctors themselves, the author raises justifiable queries, as to how the increasing importance of Evidence-Based Practice in Medicine has not induced concomitant legal modification to the Bolam test. And this, in spite of all the efforts, pushing for official guide-lines to replace Bolam. This applies, to all medical disciplines, but especially so, in the over-lapping world of two particular specialities, where obstetric action results in adverse pediatric outcome.

The 2015 ruling by the UK Supreme Court of the obstetric Scottish case Nadine Montgomery Pursuer against Lanarkshire Health Board has at least and at last, provided its own challenge to at least part of the Bolam test namely that part dealing with the disclosure of important medical information to the patient. The author agrees with Badenoch, that this is highly likely to herald further challenges to the other two aspects of the Bolam test, namely 'diagnosis' and 'treatment' [1]. If and when this happens, it is more than likely that Evidence - Based Practice will come into its own rightful place in guiding future medical jurisprudence.

One example of the nature of application of such jurisprudence in obstetric-pediatric issues, would be Cerebral Palsy. We speak of no small financial matters, aside from the heart-breaking nature of the human tragedy. Life care plans for severe Cerebral Palsy often exceed $\$ 20$ to $£ 30$ million, and higher [2].
\end{abstract}

Keywords: OBGYN; Obstetric-pediatric litigation; Evidence-Based Practice; UK Law; Medico-legal jurisprudence; Bolam test; Bolitho test; Respectable body of professional opinion; Challenge; Vacuum; Standard of care, Defensive Medicine

\section{Introduction}

Evidence - Based Practice (EBP) is today a sine qua non in all medical disciplines, including obstetrics and pediatrics. All major Colleges issue guide-lines based on EBP. Although it cannot replace personal experience, EBP enriches management by honing such experience and guiding it, with a varying level of evidence, in specific actions and lines of management. Essentially, it offers evidence varying in strength from the weaker case-controlled studies to the stronger meta-analyses, systematic reviews and randomised controlled trials. It is crucial to understand that EBP takes nothing from the practice of obstetrics and pediatrics save that which should not be there. It puts science where it ought to be, and, makes the healer, ideally poised to perform his humanitarian work, mentally at ease of scientific backing, if and when challenged. It may also be the first step in countering the bane of defensive medicine.

EBP flies bang into the face of any concept which sets the standard of practice by reference to peer practice, if the latter is based unquestioningly on tradition. Which means that $a b$ initio, EBP and the core essential of the jurisprudential Bolam test are potentially mortal enemies, unless the peer practice under scrutiny co-incides with EBP. Yet, Bolam's test, has held its ground in UK jurisprudence since 1957.

The medical world has long quietly amassed enough conscious and sub-conscious impetus to orient Court litigation along scientific evidence and not simple peer practice. Yet, although the concept of EBP has been around since the 1990's, for the last six decades, UK Law has stood by the strength of peer practice as one of its gauges of setting the legal standard of practice. This is of special significance in obstetric-pediatric jurisprudence, particularly where both specialties inter-cross at particularly vulnerable moments such as alleged mismanagement of the peri-partum period. 


\section{The Significance of Bolam}

In 1957, Hector Bolam, was neither strapped nor given a muscle relaxant prior to electro-convulsant therapy. The consent form he signed did not include the possibility of risks of fractures, which he did suffer in his hip region, when he fell off the couch. At the time, there were two schools of thought as to whether muscle relaxants and/or strapping should be employed. In Bolam $v$ Friern Hospital Management Committee, the patient sued the hospital authorities alleging damage from medical malpractice.

The Court held that there is no breach of standard of care if a responsible body of similar professionals supports the practice judged, even if this did not comply with the established standard of care [3]. Under this principle, the plaintiff needs to establish (1) the existence of a duty of care by the defendant to the plaintiff and (2) the breach of that duty of care through omission or commission, as defined by a responsible body of similar professionals. With this instruction to the (civil) jury, McNair J, laid the Bolam principle, the application of which would guide medical UK tort law for 60 years. The House of Lords gave its blessing of the principle with regard to the treatment in 1981 with Whitehouse v Jordan; with regard to diagnosis in 1985 with Maynard $v$ West Midlands Regional Health Authority; and, with some caveats, to the volunteering of information when advising patients on possible treatment, in 1992 with Sidaway $v$ Bethlem [4,5,6].

Over the last six decades, numerous cases, including uncountable OBGYN cases as well as numerous obstetric-pediatric issues have faced medical jurisprudence under this principle, enunciated by McNair J:

"The test is the standard of the ordinary skilled man exercising and professing to have that special skill. A man. need not possess the highest expert skill, it is well established law that it is sufficient if he exercises the ordinary skill of an ordinary competent man exercising' that particular art (a health care professional), is not guilty of negligence if he has 'acted in accordance with a practice accepted as proper by a responsible body of medical man skilled in the particular act" [3].

\section{The Bolitho limitation}

Among the innumerable objections raised to Bolam, has been a basic condemnation that a number of doctors may agree to state that even a banal form of management may constitute the accepted norm in use. This was countered in 1996 by a ruling resulting from Bolitho $v$ City and Hackney Health Authority - a negligence case pleaded by the mother of a deceased two year child. The plaintiff claimed that that the doctor involved (whose bleep had malfunctioned) would have intubated and saved the child had she (the doctor) been present [7]. The defendant maintained that in this particular case, even if available, she still would not have intubated. Applying the Bolam test to the case, the court ruled there was no breach of duty. At appeal, the Court upheld the ruling quoting that the medical opinion of the defendant (1) tallied with that of similar professionals, but furthermore (2) the explanation of these professionals made logical sense to the Court. The forwarded expert opinion was both defensible and logical. The Bolam and Bolitho tests are often employed in tandem.

There are those who maintain that by 'reining in', Bolam with Bolitho, the Courts have become less dependent on the medical fraternity [8]. In truth, Bolitho is of special value in opposing illogical medical opinions and this constitutes a minimal part of the spectrum of cases where Bolam needs to be applied. The great majority of cases will derive no advantage.

\section{Should Bolam's supremacy be challenged in 2017?}

Referring to the UK Legal system, Bolam, as a rule still rules the waves. Reflecting on Lord Scarman's words...For in the realm of diagnosis and treatment negligence is not established by preferring one respectable body of professional opinion to another [5].

This was in 1985, hardly a period of time, where science, can be considered in its infancy, be it in in obstetrics- pediatrics litigation, or any other speciality. In 1957, maybe neither the UK, nor the rest of Europe, was teeming with leading illuminaries of all medical specialities. Re-reading and reflecting on Bolam and Lord Scarman's words in the $21^{\text {st }}$ century, raises worrying eyebrows. No doubt, Lord Scarman elucidates the point raised by Bolam, but the point in question revolves round the meaning of a respectable body of professional opinion. Let us take a case of an adverse outcome involving a vaginal breech delivery with a damaged infant, occurring in Lancashire. Do we look for peers constituting a respectable body of professional opinion from Lancashire? Or do we seek them in London? Or Edinburgh? Would we not rather peruse the Evidence-Based Guidelines issued by the Colleges of Obstetricians and Gynaecologists/Pediatrics? Admittedly in 1957 there were neither Evidenc-Based Practice nor much of organised Colleges to formally and officially consult. But in 2017?

A potentially even more challenging subject than the mode of breech delivery vis-à-vis objectivity, would be intra-partum cardiotocographic interpretation [9]. This is no airy-fairy subject, underlying as it does, much (often wrongly so) obstetric Court litigation involving paediatric adverse outcomes, including that of Cerebral Palsy [10]. Incidentally, Cerebral Palsy litigation based solely on an Intra-Partum CTG (I - P CTG) tracing, by modern scientific principles, leaves much to be desired from jurisprudential reasoning. Examples of such I-PCTG litigation between two "expert" sides arguing vociferously on the significance of the CTG may be found in Tippett $v$ Guy's \& St Thomas' Hospital NHS Foundation Trust and Coyle v Lanarkshire Health Board. EBP based College guidelines defining Hypoxic Ischaemic Encephalopathy(HIE) criteria such as those agreed by the 2003/2014 US College of Obstetricians and Gynaecologists and the American Association of Pediatrics [11-14] do not even put I-PCTG scrutiny in the first line of primary criteria parameters of diagnosis of HIE. Bolam based I-PCTG reasoning may see two camps, both labelled 
respectable bodies of professional opinion, arguing over a plaintiff's and defendant's destiny, both making their points along Bolam's 1957 principle without even coming close to modern concepts of Cerebral Palsy reasoning. EBP guideline reasoning of the same case would, willy-nilly drag the argument into contemporary evaluation of Cerebral Palsy along the concepts of Hypoxic Ischaemic Encephalopathy. Surely an NHS forking out $£ 1.6$ billion in medico-legal claims, such as the UK's, ought to see the simple logic of the need to shift from 1957 to 2017 medico-legal mentality and philosophy of action.

\section{EBP should replace "a respectable body of professional opinion"}

The 1957 enunciation of the Bolam principle by McNair J was not out of place, at the time, in seeking a respectable body of professional opinion to assist the Court to establish the legal standard of practice. In 1957, EBP was non-existent, and the guidelines were basically what the textbook says and textbooks do rapidly go out of date. However, even by the 1960's, we do find efforts not only to standardize professional credentials but also to standardize medical procedures [15]. The wholesomeness of Bolam was jurisprudentially questioned even from the early years, and vociferously so, by the end of the $21^{\text {st }}$ century. By this time, Court could have easily established its Standard of Practice by reference to EBP as led by College and Government guide-lines. For EBP is purely based on systematically developed statements which assist practitioners and patients in decisions about appropriate health care for specific procedures and clinical circumstances [16].

Ignoring EBP based College guide-lines, say from the Colleges of Obstetricians and Pediatricians, is essentially ignoring the very voice of one very major respectable body of professional opinion, which McNair J's enunciation speaks of. How can one, for example in jurisprudentially assessing a case of Cerebral Palsy, not have, in one's Court, the relevant and latest guidelines from the Colleges of Obstetricians and of Pediatrics?

Having said all this, intelligent barristers have been using EBP based College and other guide-lines in their Court transactions and at times successfully so. For these guide-lines are based on the irrefutable march of science, even if not yet officially Court recognised as the voice which should be influencing the setting of the golden Standard of Practice. In fact, Bolam may rule de jure, but at times EBP based guide-lines take the Court floor de facto. One example comes from AW Pursuer against Greater Glasgow Health Board Defenders, a case from, the Scottish Courts of 2015 [17]. Although the ACOG-AAP 2003/2016 Criteria for diagnosing $\mathrm{HIE}$, are not mentioned as such, we find a nicely balanced choice of the criteria therein discussed, involving the main elements advocated in the guidelines to diagnose or refute HIE. No simple arguing of what respectable body of professional opinion would say about an I-P CTG tracing would have sufficed here. That is the prototype of fair, EBP based, Cerebral Palsy Court argumentation.

\section{A need to empower EBP guide-lines}

EBP guide-lines are not legally binding, and may never even be referred to, in Court. Unless, of course, the plaintiff or his defense team have done their homework and challenge the defendant to explain any deviation from such formally advised practice. In such a situation, the defendant should have adequate reasons ready to quote, as to why he departed from what is formally recommended. Adherence to guide-lines may also be a requirement by medical insurances. Guide-lines, like overviews, gather, appraise and combine evidence, but go beyond that, by addressing all the issues relevant to a clinical decision, and all parameters which may sway clinical recommendations. Although such guide-lines are not, as yet, the official Court's yardstick, in many countries, including the UK, there is vast and logical consensus among medico-legal experts, that Bolam, must eventually yield to them. Especially in situations like obstetric-pediatric jurisprudence involving on such controversial and potentially subjective topics such as intrapartum cardio-tocographic monitoring (I-P CTG) [18].

There is a general legal tendency in the UK, to lend more weighting to official guidelines such as those emanating from the Colleges or National bodies such as NICE. Technically, guide-lines may be set up by anybody, including a health authority, a hospital, be it private or not, and even a simple private clinic. One such UK IVF guide-line, issued by the Human Fertilisation and Embryology Authority (HEFA) in 1990 - limiting uterine implantation of fertilised ova to three - has been actually given the full weight of the law.

\section{We must also bear in mind the potential double-edged sword nature of legally recognised and enforceable guide-lines:}

The mere fact that a Protocol or Guideline exists for the care of a particular condition does not of itself establish that compliance with it would be reasonable in the circumstances, or that non-compliance would be negligent. As guideline-informed health care increasingly becomes customary, so acting outside the guidance of guidelines could expose doctors to the possibility of being found negligent, unless they can prove a special justification in the circumstances' [19].

And here, one must make clear the distinction between legally enforceable guide-lines and the hopeful, future recognition by the Courts of College or nationally recognised guide-lines in establishing the Standard of Practice.

\section{The first official cracks in Bolam}

The first solid challenge to Bolam was to come, as late as 2015, from a Scottish Court case, namely, Nadine Montgomery Pursuer against Lanarkshire Health Board [20]. Initially rejected first by the Scottish Courts, the plaintiff's justifiable plea was accepted by

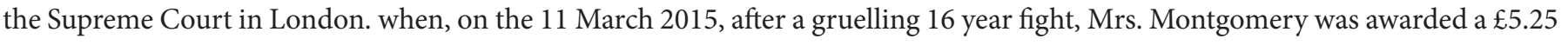


million compensation.

Nadine Montgomery, a Lanarkshire woman, in October 1999, gave birth to her first child, who sustained Cerebral Palsy, as a consequence of shoulder dystocia, during his birth. The plaintiff claimed that her obstetrician, had failed to advise her of the 9-10\% risk of shoulder dystocia in her own particular circumstances. For, Mrs Montgomery was of short stature, suffered from Type I diabetes and carried a large baby (4.25kg at birth). The possibility of C Section delivery was never brought up. This mode of delivery could have avoided the 12 minutes of hypoxia in the second stage of labour and the subsequent brain damage. In her defence, the obstetrician, surprisingly, stated that, IF she had she laid the facts and risks in front of the patient and mentioned the possibility of a C-Section, the patient would have opted for a C-Section. In other words she made it clear that she withheld important medical information, which, if disclosed to the patient, would have led to a course of action, not desired by the doctor.

The UK Supreme Court ruling in Nadine Montgomery was a direct attack on that aspect of Bolam dealing with the disclosure of information necessary for obtaining medical consent, which aspect had been given the blessing of the House of Lords in Sidaway $v$ Bethlem [6]. The Courts were now saying that the patient had a full right to know the risks of such complications. The doctor had no right to act as gate keeper as to what the patient, if compos mentis, should know.

\section{Quoting from the Solicitor's Gazette:}

Under the Bolam test, a doctor would not be found to be negligent if "he ... acted in accordance with a practice accepted as proper by a responsible body of medical men skilled in that particular art". In Sidaway, a majority of the House of Lords confirmed the application of the Bolam test, which had been applied in the context of the diagnosis and treatment of a patient, to a failure to advise a patient of risks involved in treatment.

In Montgomery, however, the UK Supreme Court reversed the judgments at first instance and on appeal, making clear that in the UK, the doctor's duty to advise her patient of the risks of proposed treatment, falls outside the scope of Bolam. This test will no longer apply to the issue of consent, although it will continue to be used more widely in cases involving other alleged acts of negligence.

The Court judgement goes beyond the fact that the doctor failed to provide the patient with sufficient information to give informed consent and thus to choose, if she wished, a Caesarean rather than a normal delivery with all its potential risks. In the words of Badenoch, it belatedly brings UK law into line with the long held and published standards of the medical profession's own regulatory body"( the GMC) [21]. Not only is the House of Lords case of Bolam over-ruled but the whole future of Bolam is also on the line in other fields of clinical practice [21].

Bolam has served its purpose, and though it has withstood previous challenges, it has, at least regarding the disclosing of information, found a much needed and belated coup de grâce in Montgomery [22]. This means that, medical jurisprudence has recognised that the 1957 enunciation, needs re-thinking and possibly complete abolishment. Among other advantages, it puts the medical profession in line with its own regulatory body(General Medical Council)'s recommendations, as well as other professions. Alleged liability involving disclosure of medical information, will now be judged by the Courts, and it will not be physicians who will decide on the requisite standard of care. Unlike Bolitho, which allows Court to accept or reject a medically set standard of care, solely on the prerogative of the narrow window of whether it makes logical sense or not, Montgomery puts all cases involving disclosure of information, within this remit, in the full control of the Court.

The Montgomery ruling has other implications, which are likely to benefit justice by eliminating the subjectivity of choice of the respectable body of professional opinion. For, once the Court has the prerogative of choice of the standard of care, it is more likely to attain the full responsibility and commitment, reminiscent of the Daubert Court. And, it is in this post-Bolam vacuum, where Court may finally put into the right perspective and give the right weighting to Evidence-Based Practice, be it in the form of College or National guide-lines (e.g.NICE) or any other title. Be it as it may, the case of Nadine Montgomery Pursuer against Lanarkshire Health Board Defenders is likely to have a direct effect on EBP, which is likely to move closer to the centre of the limelight in establishing the golden Standard of Care. And it was a case of Cerebral Palsy, admittedly of obstetric rather than pediatric involvement, which commenced this cataclysmic jurisprudential change.

\section{References}

1. Badenoch J (2016) A doctor's duty of disclosure and the decline of 'The Bolam Test': A dramatic change in the law on patient consent. Med Leg J 84: 5-17.

2. Sartwelle TP, Johnston JC (2015) Cerebral palsy litigation: change course or abandon ship. J Child Neurol 30: 828-41.

3. Bolam v Friern Hospital Management Committee [1957] 1 WLR 5829.

4. Whitehouse v Jordan [1981] 1WLR 246.

5. Maynard $v$ West Midlands Regional Health Authority [1985] 1 All ER 635.

6. Sidaway v Bethlem [1992] BMLR 11.

7. Bolitho $v$ City and Hackney Health Authority [1996] 4 All ER 771.

8. Mulheron R (2010) Trumping Bolam: A Critical Legal Analysis of Bolitho's “Gloss”. Camb Law J 69: 609-38.

9. Buttigieg GG (2016) Equivocal Court Cardiotocography Weighting in Cerebral Palsy Litigation. J For Med Leg Aff 1: 107.

10. Buttigieg GG (2017) Lessons from the Great Medico-Legal Chapter of Cerebral Palsy. J Neurol Disord 5:335.

11. Tippett v Guy's \& St Thomas' Hospital NHS Foundation Trust. [2014] EWHC 917. 
12. Coyle v Lanarkshire Health Board [2013] CSOH 167, 201.

13. The American College of Obstetricians and Gynecologists' Task Force (2003) Neonatal encephalopathy and cerebral palsy, The American College of Obstetricians and Gynecologists, the American Academy of Pediatrics. Neonatal encephalopathy and cerebral palsy: Defining the pathogenesis and pathophysiology. Washington, DC: The American College of Obstetricians and Gynecologists 2003: 1-85.

14. (2014) Executive summary: Neonatal encephalopathy and neurologic outcome, second edition. Report of the American College of Obstetricians and Gynecologists' Task Force on Neonatal Encephalopathy. Obstet Gynecol. 123: 896-901.

15. Weisz G, Cambrosio A, Keating P, Knaapen L, Schlich T, et al. (2007) The emergence of clinical practice guidelines. Milbank Q 85: 691-727.

16. Schwartz PJ, Breithardt G, Howardt AJ, Julian DG, Ahlberg NR (1999) The legal implications of medical guidelines - a Task Force of the European Society of Cardiology. Eur Heart J (1999) 20: 1152-7.

17. AW Pursuer against Greater Glasgow Health Board Defenders [2015] CSOH 99.

18. Buttigieg GG (2016) The shifting sands of medico-legal intra-partum Ctg (I-P Ctg) monitoring. Med Leg J 84: 42-5.

19. Hayward RS, Wilson MC, Tunis SR, Bass EB, Guyatt G (1995) Users' guides to the medical literature. VIII. How to use clinical practice guidelines. A. Are the recommendations valid? The Evidence-Based Medicine Working Group. JAMA 274: 570-4.

20. Nadine Montgomery Pursuer against Lanarkshire Health Board Defenders [2010] CSOH 104.

21. Badenoch J (2016) A doctor's duty of disclosure and the decline of 'The Bolam Test': A dramatic change in the law on patient consent. Med Leg J 84: 5-17.

22. Buttigieg GG (2017) Submitting medico-legal intra-partum CTG (I-P CTG) monitoring to the Bolam and Bolitho principles. Med Leg J 85: 93-6. 